\title{
Sulfur respiration in a marine chemolithoautotrophic Beggiatoa strain
}

\section{Anne Schwedt *, Anne-Christin Kreutzmann, Lubos Polerecky and Heide N. Schulz-Vogt}

Max Planck Institute for Marine Microbiology, Bremen, Germany

Edited by:

Niels-Ulrik Frigaard, University of

Copenhagen, Denmark

\section{Reviewed by:}

Rich Boden, Plymouth University, UK

Blanca Barquera, Rensselaer

Polytechnic Institute, USA

*Correspondence:

Anne Schwedt, Max Planck Institute

for Marine Microbiology,

Celsiusstraße 1, 28359 Bremen,

Germany.

e-mail: aschwedt@mpi-bremen.de

\begin{abstract}
The chemolithoautotrophic strain Beggiatoa sp. 35Flor shows an unusual migration behavior when cultivated in a gradient medium under high sulfide fluxes. As common for Beggiatoa spp., the filaments form a mat at the oxygen-sulfide interface. However, upon prolonged incubation, a subpopulation migrates actively downward into the anoxic and sulfidic section of the medium, where the filaments become gradually depleted in their sulfur and polyhydroxyalkanoates (PHA) inclusions. This depletion is correlated with the production of hydrogen sulfide. The sulfur- and PHA-depleted filaments return to the oxygen-sulfide interface, where they switch back to depositing sulfur and PHA by aerobic sulfide oxidation. Based on these observations we conclude that internally stored elemental sulfur is respired at the expense of stored PHA under anoxic conditions. Until now, nitrate has always been assumed to be the alternative electron acceptor in chemolithoautotrophic Beggiatoa spp. under anoxic conditions. As the medium and the filaments were free of oxidized nitrogen compounds we can exclude this metabolism. Furthermore, sulfur respiration with PHA under anoxic conditions has so far only been described for heterotrophic Beggiatoa spp., but our medium did not contain accessible organic carbon. Hence the PHA inclusions must originate from atmospheric $\mathrm{CO}_{2}$ fixed by the filaments while at the oxygensulfide interface. We propose that the directed migration of filaments into the anoxic section of an oxygen-sulfide gradient system is used as a last resort to preserve cell integrity, which would otherwise be compromised by excessive sulfur deposition occurring in the presence of oxygen and high sulfide fluxes. The regulating mechanism of this migration is still unknown.
\end{abstract}

Keywords: Beggiatoa, sulfur reduction, gradient cultivation, microelectrodes, migration

\section{INTRODUCTION}

The genus Beggiatoa comprises large, filamentous bacteria that inhabit diverse sulfidic environments, such as sediments (Winogradsky, 1887; Jørgensen, 1977; Nelson and Castenholz, 1982; McHatton et al., 1996), springs (Winogradsky, 1887; Macalady et al., 2006), and activated sludge (Farquhar and Boyle, 1971). The motile filaments typically aggregate in a narrow overlapping zone of opposed oxygen and sulfide diffusion gradients where they form a sharply demarcated mat (Faust and Wolfe, 1961; Nelson and Jannasch, 1983; Nelson et al., 1986). Within this mat, Beggiatoa spp. oxidize sulfide with oxygen, depleting both compounds (Nelson et al., 1986). This process is accompanied by deposition of elemental sulfur inside the filaments.

Several filamentous and non-filamentous members of the Beggiatoaceae (Salman et al., 2011) are capable of anaerobic sulfide oxidation with nitrate as electron acceptor (Fossing et al., 1995; McHatton et al., 1996; Schulz et al., 1999). Dissimilatory nitrate reduction enables these organisms to colonize anoxic environments such as deeper layers in sediments, microbial mats, or gradient cultures (Sweerts et al., 1990; Mussmann et al., 2003; Sayama et al., 2005; Kamp et al., 2006; Hinck et al., 2007; Jørgensen et al., 2010). Nitrate-based sulfide oxidation seems to have been of great importance for some members of the Beggiatoaceae, as suggested by their ability to highly concentrate nitrate from the ambient water and store it in intracellular vacuoles (Fossing et al., 1995; McHatton et al., 1996; Schulz et al., 1999; Sayama, 2001; Mussmann et al., 2003; Kalanetra et al., 2004, 2005; Hinck et al., 2007). For example, internal nitrate concentrations of 4$44 \mathrm{mM}$ were found in narrow, hypersaline Beggiatoa spp. cultivated at an external nitrate concentration of $50 \mu \mathrm{M}$ (McHatton et al., 1996), whereas up to $100-800 \mathrm{mM}$ of nitrate were reported for marine Thiomargarita spp. cells from an environment with ambient nitrate concentrations of 5-28 $\mu \mathrm{M}$ (Schulz et al., 1999). However, also non-vacuolated strains were shown to use externally provided nitrate as a terminal electron acceptor (Sweerts et al., 1990; Kamp et al., 2006).

We cultivated the chemolithoautotrophic, marine strain Beggiatoa sp. 35Flor in an agar-stabilized oxygen-sulfide gradient medium. Upon prolonged incubation in the presence of medium to high sulfide fluxes, we observed an unusual migration behavior, where a subpopulation of filaments moved downward from the oxygen-sulfide interface. These filaments were able to survive although sulfide concentrations were high and terminal electron acceptors that are known to be used by Beggiatoa spp., i.e., oxygen and nitrate, were not detectable in the medium or the filaments. In this study we investigated the possibility of an alternative 
metabolism of Beggiatoa sp. 35Flor under anoxic, nitrate-free, and sulfidic conditions, and discuss its possible ecological significance and link to the peculiar migration behavior.

\section{MATERIALS AND METHODS STRAIN AND CULTIVATION}

The strain Beggiatoa sp. 35Flor was enriched from a black band disease of scleractinian corals from the coast of Florida. The filaments are about $6 \mu \mathrm{m}$ wide (Kamp et al., 2008), and the cells contain a central vacuole filled with polyphosphate (Brock and Schulz-Vogt, 2011). The strain can so far only be cultivated in the presence of Pseudovibrio sp. FO-BEG1, which was isolated in pure culture from the very same enrichment (Schwedt, unpublished). Different attempts of obtaining a pure culture of Beggiatoa sp. 35Flor failed so far, indicating that there is an important interaction between these strains. However, the nature of this interaction is currently not resolved and might not be specific. The clonal Beggiatoa culture used in this study was eventually obtained by inoculating gradient media with a single, washed filament (Schulz-Vogt, unpublished).

Cultivation was performed in tubes with an agar-based mineral gradient medium designed for chemolithoautotrophic growth of Beggiatoa spp. (Nelson et al., 1982; Nelson and Jannasch, 1983) using artificial seawater (Kamp et al., 2008). The medium was composed of a sulfidic bottom agar plug ( $1.5 \% \mathrm{w} / \mathrm{v}$ agar $)$ covered with a sulfide-free, semisolid top agar layer $(0.25 \% \mathrm{w} / \mathrm{v}$ agar) of $\sim 5 \mathrm{~cm}$ height. Both agar layers were prepared by mixing separately autoclaved salt and agar solutions. The salt solution comprised $100 \mathrm{~mL}$ artificial seawater $(470.57 \mathrm{mM} \mathrm{NaCl}, 24.6 \mathrm{mM}$ $\mathrm{MgCl}_{2} \cdot 6 \mathrm{H}_{2} \mathrm{O}, 16.6 \mathrm{mM} \mathrm{MgSO}_{4} \cdot 7 \mathrm{H}_{2} \mathrm{O}, 4.5 \mathrm{mM} \mathrm{CaCl}_{2} \cdot 2 \mathrm{H}_{2} \mathrm{O}$ and $13.7 \mathrm{mM} \mathrm{KCl} ; 27.5 \mathrm{~g} \mathrm{NaCl}, 5 \mathrm{~g} \mathrm{MgCl}_{2} \cdot 6 \mathrm{H}_{2} \mathrm{O}, 4.1 \mathrm{~g} \mathrm{MgSO}_{4} \cdot 7 \mathrm{H}_{2} \mathrm{O}$, $0.66 \mathrm{~g} \mathrm{CaCl}_{2} \cdot 2 \mathrm{H}_{2} \mathrm{O}$, and $1.02 \mathrm{~g} \mathrm{KCl}$ in $1 \mathrm{~L}$ distilled water), $2.9 \mathrm{~g}$ $\mathrm{NaCl}$, and 1 drop of $1 \mathrm{~mol} \mathrm{~L}^{-1} \mathrm{KOH}$ in case of the bottom agar medium, or $240 \mathrm{~mL}$ artificial seawater and $4.32 \mathrm{~g} \mathrm{NaCl}$ in case of the top agar medium. The agar solution contained $80 \mathrm{~mL}$ distilled water and $2.7 \mathrm{~g}$ double-washed agar (bottom agar medium), or $96 \mathrm{~mL}$ distilled water and $0.9 \mathrm{~g}$ double-washed agar (top agar medium). The top agar medium further received sterile mineral solution $\left(3.2 \mathrm{mM} \mathrm{K}_{2} \mathrm{HPO}_{4}, 139.5 \mu \mathrm{M} \mathrm{Na} \mathrm{MoO}_{4}, 3.9 \mathrm{mM}\right.$ $\mathrm{Na}_{2} \mathrm{~S}_{2} \mathrm{O}_{5}$, and $107.3 \mu \mathrm{M} \mathrm{FeCl}_{3} \cdot 6 \mathrm{H}_{2} \mathrm{O} ; 555 \mathrm{mg} \mathrm{K} \mathrm{HPO}_{4}, 28.72 \mathrm{mg}$ $\mathrm{Na}_{2} \mathrm{MoO}_{4}, 750 \mathrm{mg} \mathrm{Na} \mathrm{S}_{2} \mathrm{O}_{5}, 29 \mathrm{mg} \mathrm{FeCl} \cdot 6 \mathrm{H}_{2} \mathrm{O}$ in $1 \mathrm{~L}$ distilled water), trace element, and vitamin solutions as specified in Kamp et al. (2008) as well as $0.72 \mathrm{~mL}$ of a sterile $1 \mathrm{~mol} \mathrm{~L}^{-1} \mathrm{NaHCO}_{3}$ solution. The bottom agar medium was supplemented with $0.7-$ $3.6 \mathrm{~mL}$ sterile $1 \mathrm{~mol} \mathrm{~L}^{-1} \mathrm{Na}_{2} \mathrm{~S}$ (4-20 mM final concentration), depending on the experiment. The medium was prepared free of nitrate, nitrite, and nitric oxide, as verified by measurements with an $\mathrm{NO}_{\mathrm{X}}$ analyzer (CLD 66, Eco Physics, Rösrath, Germany). Gas exchange with the atmosphere was possible, and opposing gradients of oxygen and sulfide were allowed to form for 1 to 2 days before inoculation. The cultures were inoculated about $1 \mathrm{~cm}$ below the air-agar interface using $100 \mu \mathrm{L}$ of filament suspension from an established mat. The cultures, from which the inoculum was taken, were prepared as described above and grown under low sulfide flux conditions for 6-10 days. The inoculum contained Beggiatoa sp. 35Flor filaments and Pseudovibrio sp. FO-BEG1 cells and was free of oxidized nitrogen species as confirmed with an $\mathrm{NO}_{\mathrm{X}}$ analyzer. All incubations were performed at room temperature in the dark.

Migration behavior of the Beggiatoa sp. 35Flor filaments was investigated in culture tubes with variable fluxes of sulfide from the bottom agar. During these incubations, the distribution of filaments in the same tube was determined simultaneously with vertical profiles of $\mathrm{H}_{2} \mathrm{~S}$ and $\mathrm{pH}$. Filaments from parallel culture tubes were subsampled and used for microscopic determination of their sulfur and PHA inclusions. Additional parallel tubes were used for the measurement of oxygen and sulfide fluxes, the proportion of broken filaments and the internal sulfur content.

\section{TRANSFER EXPERIMENT WITH SULFUR-FREE FILAMENTS}

To verify that sulfur-free filaments from the anoxic subpopulation of an aged culture (cultivated under high sulfide flux) were alive, able to migrate back to the oxygen-sulfide interface and re-establish their sulfide-oxidizing metabolism, they were transferred into the anoxic section of a fresh gradient medium (low sulfide flux conditions). All cultivation media were prepared in plexiglass tubes $(2 \times 12 \mathrm{~cm}$ in size $)$ with lateral holes (Brock and Schulz-Vogt, 2011). Fresh medium for inoculation with sulfur-free filaments was pre-incubated with Pseudovibrio sp. FO-BEG1. This was done to ensure a sufficient cell density of the accompanying bacterium irrespective of the inoculum as it seems to be required for growth of Beggiatoa sp. 35Flor but its abundance is negligible in the anoxic part of the gradient medium. Subsequently, sulfur-free filaments were removed laterally from the aged culture and injected laterally into the fresh medium at a depth of about $1 \mathrm{~cm}$ below the oxygen-sulfide interface. The media were inspected visually for development of a mat.

\section{MICROSENSOR MEASUREMENTS}

Microsensors for $\mathrm{O}_{2}$ (OX-10 standard), $\mathrm{H}_{2} \mathrm{~S}\left(\mathrm{H}_{2} \mathrm{~S}-10\right)$, and $\mathrm{pH}$ ( $\mathrm{pH}-10)$ were purchased from Unisense A/S (Aarhus, Denmark). The external reference for the $\mathrm{pH}$ electrode was manufactured and connected in-house. Calibration of the $\mathrm{H}_{2} \mathrm{~S}$ sensor was performed in anoxic, acidified artificial seawater $(\mathrm{pH}<2)$ to which anoxic $\mathrm{Na}_{2} \mathrm{~S}$ stock solution was added stepwise. The exact sulfide concentration of the stock solution was determined by iodometric titration. Total sulfide $\left(\mathrm{S}_{\text {tot }}\right)$ profiles were calculated from measured $\mathrm{H}_{2} \mathrm{~S}$ and $\mathrm{pH}$ profiles using the equation $\mathrm{S}_{\text {tot }}=\mathrm{H}_{2} \mathrm{~S} \times\left[1+K_{1} / \mathrm{H}_{3} \mathrm{O}^{+}\right]$, with $\mathrm{p} K_{1}=6.569$ at $21^{\circ} \mathrm{C}$ and $39 \%$ o salinity (Millero et al., 1988). The oxygen sensor was two-point calibrated in a calibration chamber filled with artificial seawater. Signal readings were taken in water saturated with $\mathrm{N}_{2}$ and ambient air. Oxygen concentrations at the respective salinity and temperature were calculated according to Weiss (1970). The pH electrode was calibrated using buffer solutions of $\mathrm{pH} 4.01, \mathrm{pH}$ 7.00, and pH 9.21 (Mettler-Toledo, Giessen, Germany). All sensors were calibrated immediately before the measurement. In case of long time series measurements the sensor calibration was checked afterward and a possible drift was corrected for. Sulfide fluxes were calculated using Fick's first law of diffusion $(J=-D \partial c / \partial x)$. The diffusion coefficient $D$ for $\mathrm{HS}^{-}$was corrected for temperature $\left(21^{\circ} \mathrm{C}\right)$ according to Jørgensen and Revsbech (1983), resulting in a value of $1.56 \times 10^{-9} \mathrm{~m}^{2} \mathrm{~s}^{-1}$. 
Vertical profiling in $250 \mu \mathrm{m}$ steps was performed with sensors mounted on a motorized linear positioner (VT-80, Pollux motor, Micos, Eschbach, Germany) controlled by a computer using a software tool for automated microsensor measurements ( $\mu$-Profiler, L. Polerecky, http://www.microsen-wiki.net). The sensors were aligned by manually adjusting their tips to the air-agar interface using a dissecting microscope (Stemi 2000-C, Zeiss, Jena, Germany).

\section{FILAMENT IMAGING}

The distribution of sulfur-containing Beggiatoa sp. 35Flor filaments in gradient cultures was monitored using time-lapse photography. An amber light-emitting diode (LXHL-NM98, Luxeon, Philips, San Jose, CA, USA) was positioned below the culture tube and switched on for $1 \mathrm{~s}$ when an image was taken with a cooled CCD camera (Sensicam, PCO, Kelheim, Germany). Illumination and image acquisition in $10 \mathrm{~min}$ intervals were controlled by a custom-written computer program (Look@Molli, B. Grunwald, http://www.microsen-wiki.net).

Intensities in the recorded images were horizontally averaged over an area with visible filaments ( $\sim 5 \mathrm{~mm}$ wide, $\sim 2 \mathrm{~cm}$ high), and the resulting vertical profiles were assembled into a $2 \mathrm{D}$ map with the $x$-axis representing incubation time and the $y$-axis corresponding to depth. Since the average image intensity was proportional to the density of sulfur globules, which were present exclusively inside filaments, vertical movement of sulfur-rich filaments was detected as a change in the shape of the vertical intensity profile. In contrast, an increase and decrease in the profile intensity that was not accompanied with the change in the profile shape indicated accumulation and depletion of sulfur inside the filaments, respectively. Because this method relied on light scattering from sulfur inclusions, it did not allow visualization of sulfur-free filaments.

\section{STAINING OF INTERNAL PHA}

Staining with Nile Red was used to visualize PHA inclusions in the filaments. A subsample of $90 \mu \mathrm{L}$ from a culture tube was incubated for 5 min with $10 \mu \mathrm{L}$ of a Nile Red (Sigma-Aldrich, Steinheim, Germany) staining solution $\left(25 \mathrm{mg} \mathrm{L}^{-1}\right.$ in dimethyl sulfoxide). The filament suspension was transferred onto a poly-L-lysine (Sigma-Aldrich) coated microscope slide for immobilization of the filaments. Fluorescence of Nile Red was excited with a laser at $546 \mathrm{~nm}$ and emission was recorded above $590 \mathrm{~nm}$ (filter set 15, Zeiss, Jena, Germany) using an epifluorescence microscope (Axiophot equipped with AxioCam MRm, Zeiss, Jena, Germany).

\section{IDENTIFICATION OF INTERNAL SULFUR}

Under a bright-field microscope, internal sulfur globules in Beggiatoa spp. usually appear as highly refractive, round inclusion bodies inside the filaments. We used high performance liquid chromatography (HPLC) to confirm that the globules observed in the studied strain Beggiatoa sp. 35Flor were indeed composed of sulfur. A suspension of filaments was fixed with $3.2 \%(\mathrm{v} / \mathrm{v})$ formaldehyde for $2 \mathrm{~h}$ at room temperature. Two $1 \mathrm{~mL}$ subsamples were mixed with $2 \mathrm{~mL}$ artificial seawater or HPLC-grade methanol (Applichem, Darmstadt, Germany), and shaken over night in glass vials. Filaments from both treatments were examined microscopically the next day. The methanol extract was centrifuged at
$13.000 \mathrm{rpm}$ (Centrifuge 5417R, Eppendorf, Hamburg, Germany) for $5 \mathrm{~min}$ to remove agar and cell debris. The supernatant was filtered (Acrodisc syringe filter 4472, Pall Life Science, NY, USA) and subsequently measured by HPLC (Kamyshny et al., 2009), using elemental sulfur standards as reference.

\section{MONITORING OF BEGGIATOA sp. 35FLOR CELL INTEGRITY}

The proportion of damaged filaments in cultures grown for 7 and 13 days under low and high sulfide flux conditions was quantified by visual inspection using a microscope. Samples of the mat at the oxygen-sulfide interface were taken from three parallel tubes per sulfide flux treatment, and the proportion was calculated from about 150-200 filaments counted per each sample. The significance of differences between treatments (high vs. low sulfide flux) and points of time were evaluated with a $t$-test, using logtransformed percentages of damaged filaments to ensure variance homogeneity between the compared data sets.

\section{RESULTS}

\section{MIGRATION OF BEGGIATOA sp. 35FLOR IN GRADIENT CULTURES}

Beggiatoa sp. 35Flor filaments aggregated and formed a dense mat at the oxygen-sulfide interface within the gradient medium (Figure 2A and Movie S1 in Supplementary Material). In cultures with medium to high sulfide fluxes (Table 1) a subpopulation of filaments began a downward migration to the anoxic zone about 3-4 days after establishment of the mat. For medium sulfide fluxes, this migration resulted in a layer with homogenous filament density extending up to $2-3 \mathrm{~mm}$ below the mat (Figure 1). In contrast, for high sulfide fluxes, the migrating filaments were not homogeneously distributed but progressively aggregated in a region distinctly separated from the mat at the oxygen-sulfide interface (Figures $\mathbf{1}$ and $\mathbf{2 B}$ ). Because the aggregation of filaments in the anoxic part increased the chance of detecting metabolic products all further experiments were conducted with cultures growing under a high sulfide flux.

Migration of filaments in cultures with a high sulfide flux followed a general pattern illustrated in Figure 2E. During the initial 3-4 days of incubation, the mat at the oxygen-sulfide interface gradually formed. After about 6-7 days the sulfur-globule density in the mat decreased moderately, followed by a more pronounced decrease after 8-9 days. These decreases were correlated with two pronounced events of downward migration at days 5-6 and 7-8, respectively (arrows 1 and 2 in Figure 2E). After reaching a depth of

Table 1 | Diffusive sulfide fluxes in gradient cultures from this study.

\begin{tabular}{lll}
\hline $\begin{array}{l}\mathbf{N a}_{\mathbf{2}} \mathbf{S} \text { ( } \mathbf{m m o l ~ L} \\
\text { in bottom agar }\end{array}$ & Time (days) & Flux $\left(\mathbf{m m o l ~} \mathbf{~}^{\mathbf{- 2}} \mathbf{d a y}^{\mathbf{- 1}}\right)^{\mathbf{a}}$ \\
\hline 4 (low flux) & 7 & \\
& 13 & $4.7 \pm 1.2$ \\
10 (medium flux) & 7 & $6.8 \pm 0.3$ \\
& 13 & $14.1 \pm 1.9$ \\
16 (high flux) & 7 & $14.7 \pm 1.7$ \\
& 13 & $27.3 \pm 5.1$ \\
& & $17.1 \pm 3.5$ \\
\hline
\end{tabular}

${ }^{a}$ The flux values are given as average $\pm S D$ of parallel measurements in five tubes. 
around $10 \mathrm{~mm}$, the migrating filaments formed a layer of increased filament density. These filaments slowly disappeared from view due to a gradual loss of their internal sulfur granules. The disappearance of filaments was accompanied by a parallel increase in the sulfur-globule density in the mat at the oxygen-sulfide interface (arrow 3 in Figure 2E), suggesting that the sulfur-depleted filaments returned to this zone and switched back to sulfide oxidation, thereby depositing sulfur. This was confirmed by transfer experiments, which showed that sulfur-depleted filaments transferred from the anoxic subpopulation of an aged culture into the anoxic section of a fresh gradient medium formed, within 12 days, a new mat of sulfur-containing filaments at the oxygen-sulfide interface.

\section{SULFIDE PRODUCTION BY FILAMENTS IN THE ANOXIC SECTION}

Throughout the incubation, sulfide oxidation in the mat at the oxygen-sulfide interface was confirmed by pronounced acidification and steep gradients of total sulfide (Figures 2C,D). A small but detectable peak in the $\mathrm{H}_{2} \mathrm{~S}$ profile was observed at a depth of $\sim 10 \mathrm{~mm}$ when the anoxic subpopulation was present (Figure 2D). As $\mathrm{pH}$ varied only smoothly with depth in this region, the $\mathrm{H}_{2} \mathrm{~S}$ peak was not caused by $\mathrm{pH}$ variation but indicated a true production of sulfide at and around this depth. This production was strongly spatially and temporally correlated with the presence of the anoxic subpopulation (Figure 2F), suggesting that it was linked to the metabolic activity of the filaments from this subpopulation.

\section{CELL INTEGRITY, SULFUR AND PHA CONTENT OF SINGLE FILAMENTS}

Beggiatoa sp. 35Flor filaments accumulated elemental sulfur and PHA during growth at the oxygen-sulfide interface. Sulfur inclusions were visible as dark, highly refractive globules in bright-field micrographs (Figures 3A,B). These globules disappeared when filaments were treated with methanol, and the corresponding extracts featured a single pronounced peak in the HPLC chromatogram at the retention time of $3.738 \mathrm{~min} \pm 0.007(n=27)$, which matched the sulfur standard peak at $3.728 \mathrm{~min} \pm 0.006$

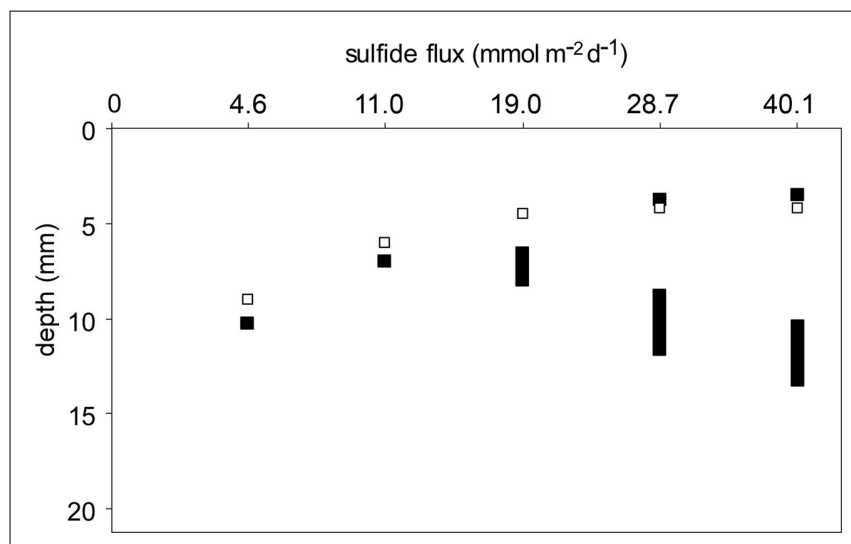

FIGURE 1 | Distribution of Beggiatoa sp. 35Flor filaments over depth in gradient cultures with different sulfide fluxes after 6 (open symbols) and 12 (closed symbols) days of cultivation. The flux values were estimated from measurements after 7 days (Table 1). $(n=9)$. PHA inclusions appeared as strongly fluorescent globules in images of Nile Red-stained samples (Figure 3E). With increasing sulfide flux the amount of internal sulfur strongly increased (compare Figures 3A,B), whereas PHA inclusions were equally abundant in all treatments (data not shown). When grown under high sulfide flux, most filaments from the mat at the oxygensulfide interface were densely filled with sulfur and PHA inclusions (Figures 3B,E). In contrast, filaments from the anoxic subpopulation were heterogeneous with respect to their inclusion density; while some were densely filled with sulfur and PHA, others lacked both (Figures 3D,F).

The proportion of damaged filaments (Figure 3C) from the mat at the oxygen-sulfide interface increased with sulfide flux. In cultures growing for 1 week under low sulfide flux, most filaments were intact, with only $0.9 \% \pm 1.0(n=3)$ filaments damaged, whereas this proportion was significantly higher $(13.2 \% \pm 3.3$, $n=3, p=0.011$ ) in cultures grown at high sulfide flux. The proportion of damaged filaments also increased with time: after 2 weeks of growth, this increase was significant for cultures with high sulfide flux $(50.1 \% \pm 7.2, n=3, p=0.007)$ but not in cultures with low sulfide flux $(2.0 \% \pm 1.5, n=3, p=0.429)$.

\section{DISCUSSION}

Sulfide production by members of the genus Beggiatoa is known from chemoheterotrophic strains that were cultivated in liquid medium and artificially exposed to short-term anoxic conditions (Schmidt et al., 1987). Based on those experiments it was hypothesized that sulfur respiration may provide Beggiatoa spp. in gradient systems with energy for return from the anoxic zone to the oxygensulfide interface under changing environmental conditions. In this study, we cultivated the chemolithoautotropically growing strain Beggiatoa sp. 35Flor in an oxygen-sulfide gradient medium, and observed a directed migration of the filaments from the oxygensulfide interface into the anoxic and sulfidic zone where they reduced internal sulfur to sulfide. This suggested an alternative or additional function of sulfur respiration in Beggiatoa filaments.

We propose that the observed behavior is a "last resort" survival strategy of Beggiatoa sp. 35Flor at prolonged incubation under high sulfide fluxes. Under this condition the filaments become densely filled with sulfur and were often observed to burst. By moving to the anoxic zone of the gradient system, the filaments can prevent further deposition of sulfur through aerobic sulfide oxidation and even reduce the amount of storage compounds by sulfur respiration with PHA. Sulfur-depleted filaments can eventually migrate back to the oxygen-sulfide interface, where they resume aerobic sulfide oxidation and accumulate new sulfur globules. An involvement of the accompanying Pseudovibrio sp. strain in the observed migration and metabolism is unlikely due to its negligible abundance in the region of the anoxic subpopulation (Schwedt, unpublished).

\section{SULFUR RESPIRATION FOR REGULATION OF THE AMOUNT OF STORED SULFUR}

The alternation between sulfide oxidation and sulfur reduction in spatially separated environments seems to allow Beggiatoa sp. 35Flor to control the amount of stored sulfur beyond the scope of enzymatic regulation. Sulfide is oxidized aerobically by 
Beggiatoa spp. in a two-step process via internally stored sulfur $\left(2 \mathrm{H}_{2} \mathrm{~S}+\mathrm{O}_{2} \rightarrow 2 \mathrm{~S}^{0}+2 \mathrm{H}_{2} \mathrm{O}\right)$ further to sulfate $\left(2 \mathrm{~S}^{0}+3 \mathrm{O}_{2}+\right.$ $\left.2 \mathrm{H}_{2} \mathrm{O} \rightarrow 2 \mathrm{SO}_{4}^{2-}+4 \mathrm{H}^{+}\right)$. The regulation of these reactions is unknown in Beggiatoa spp., but the presence of internal sulfur globules demonstrates that the two reactions are not always well balanced. Principally, a balanced sulfur content can be achieved by either down-regulating sulfide oxidation or up-regulating sulfur oxidation. Possibly, sulfide oxidation is controlled kinetically and cannot be regulated by the cell, because both $\mathrm{O}_{2}$ and $\mathrm{H}_{2} \mathrm{~S}$ freely diffuse into the cytoplasm. This is supported by observations on other closely related filamentous and non-filamentous large sulfur bacteria, which both immediately increase their respiration rate upon addition of sulfide to the medium (Schulz and de Beer, 2002; Høgslund et al., 2009). Moreover, Fenchel and Bernard (1995) reported for marine Beggiatoa spp. that the sulfide flux into the mat did not drop after the oxygen flux was decreased, indicating that the ratio of sulfide oxidation to sulfur oxidation shifted to favor sulfide. Therefore, up-regulation of sulfur oxidation seems the more likely mechanism to balance the internal sulfur content. However, at high sulfide fluxes the frequently observed bursting of Beggiatoa sp. 35Flor filaments that were densely filled with sulfur globules indicates that

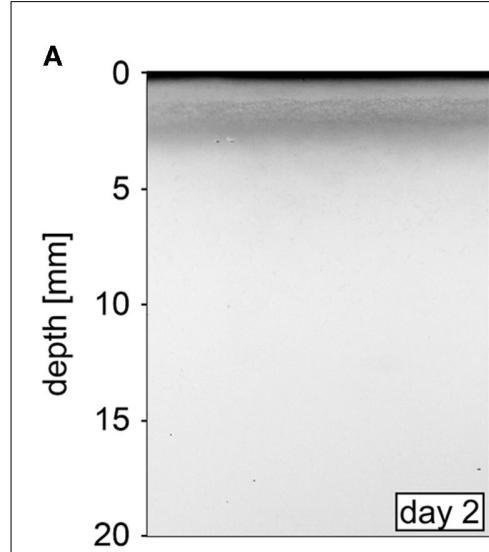

C

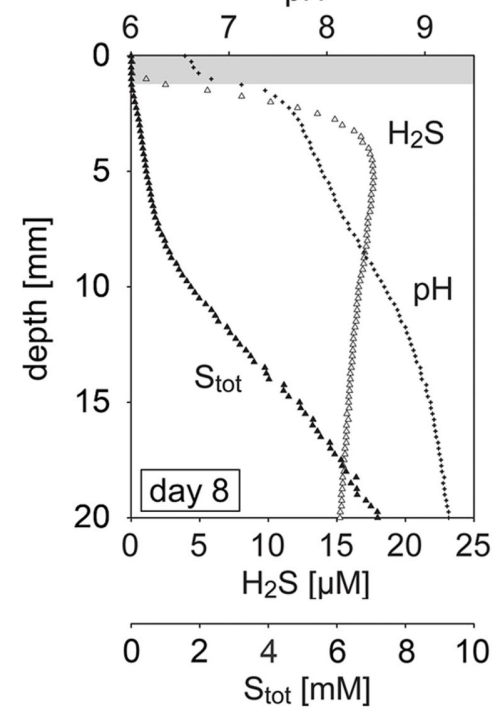

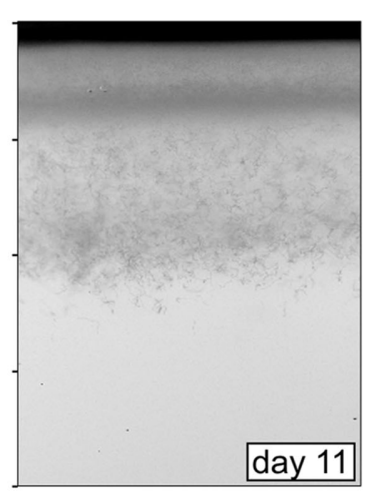

D

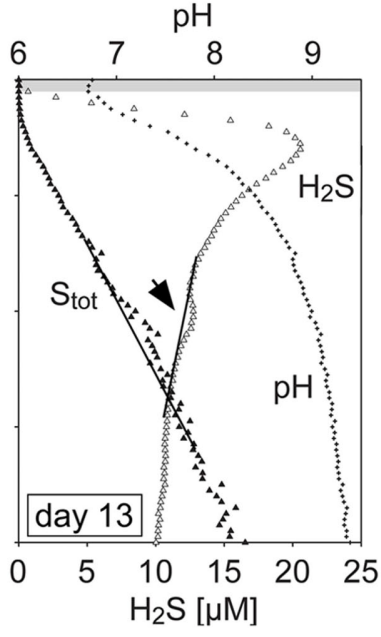

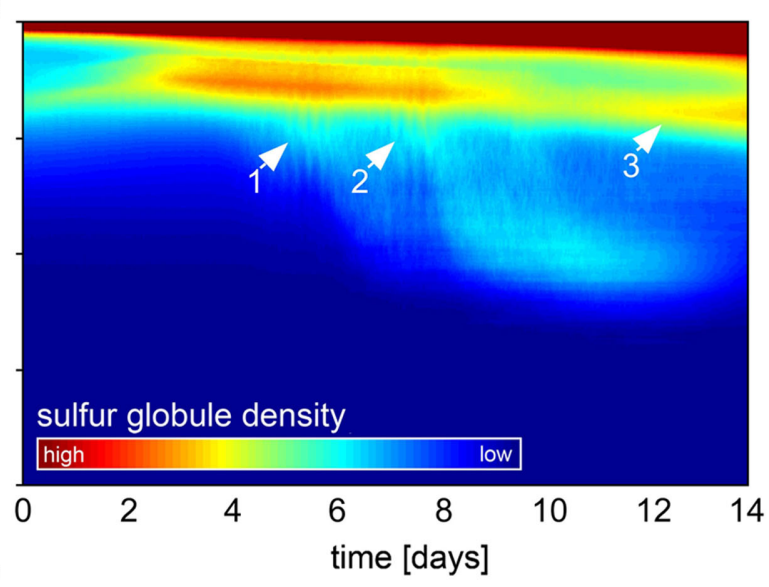

$\mathbf{F}$

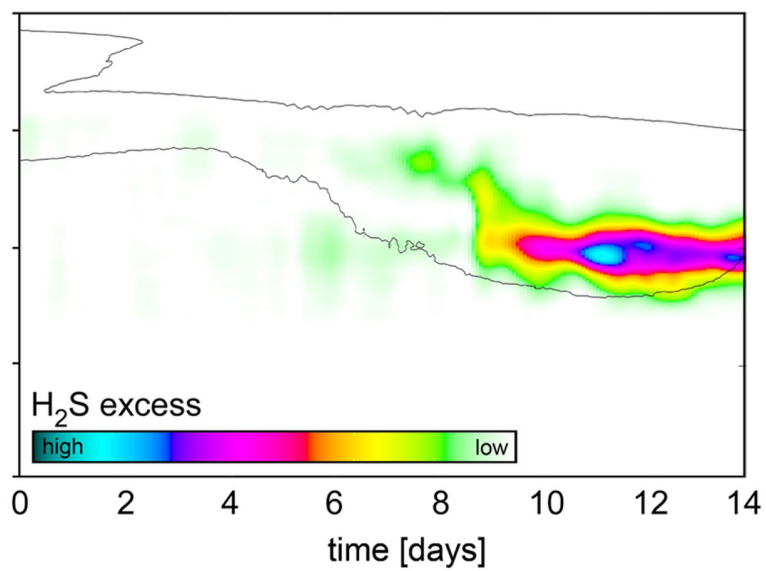

FIGURE 2 | Relationship between the migration of Beggiatoa sp. 35Flor filaments and the dynamics of $\mathrm{O}_{2}, \mathrm{pH}, \mathrm{H}_{2} \mathrm{~S}$, and $\mathrm{S}_{\text {tot }}$ (total sulfide) in gradient cultures with high sulfide flux. (A+B) Images of culture tubes showing the filament distribution after 2 and 11 days. (C+D) Examples of $\mathrm{pH}$, $\mathrm{H}_{2} \mathrm{~S}$, and total sulfide profiles in 8- and 13-day-old gradient cultures. Shaded areas mark the oxic zone. (E) Average sulfur-globule density as a function of time and depth, showing the dynamics of the filament distribution and their sulfur content. Arrows 1 and 2 indicate the onset of major downward migration events, arrow 3 indicates the onset of an increase in the filament density in the mat at the oxygen-sulfide interface. Although the timing of these events varied amongst experimental runs, the general pattern was reproducible. A time-lapse movie of migrating filaments, from which the sulfur-globule density plot was calculated, is provided as a supplementary material (Movie S1 in Supplementary Material). (F) $\mathrm{H}_{2} \mathrm{~S}$ excess as a function of time and depth, calculated by subtracting the measured $\mathrm{H}_{2} \mathrm{~S}$ profile from the background trend. The trend was derived from the $\mathrm{H}_{2} \mathrm{~S}$ concentrations measured above and below the peak [line indicated by arrow in (D)]. Contour lines of the sulfur-globule density from (E) are overlaid. Data shown in $\mathbf{( A , B , E , F )}$ are from the same culture tube, profiles in $(\mathbf{C}, \mathbf{D})$ are from a parallel culture tube. 


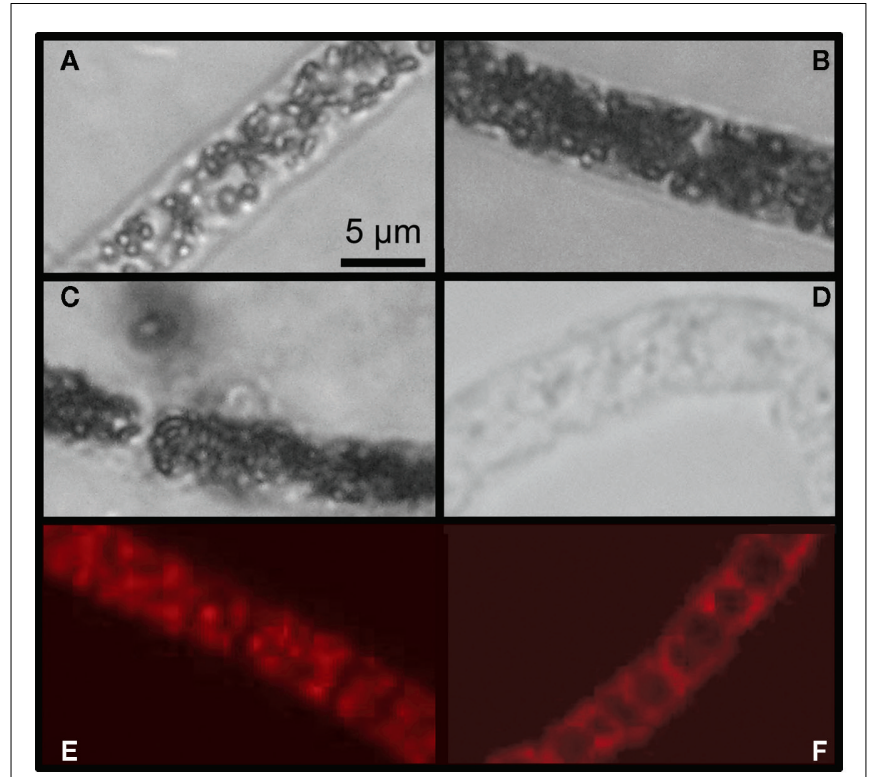

FIGURE 3 | Bright-field and fluorescence micrographs illustrating the typical appearance of Beggiatoa sp. 35Flor filaments cultivated under different conditions. $(\mathbf{A}+\mathbf{B})$ Filaments from the mat the oxygen-sulfide interface of 6-days-old cultures growing under low (A) and high (B) sulfide flux conditions. (C+D) Filaments from cultures grown under high sulfide flux conditions, collected from the mat at the oxygen-sulfide interface after 27 days (C) and from the anoxic subpopulation after 12 days (D). (E + F) Nile Red-stained filaments from a 14-day-old culture, collected from the mat at the oxygen-sulfide interface (E) and from the anoxic subpopulation (F). Bright fluorescence in (E) originates from PHA inclusions, whereas lower fluorescence in $(\mathbf{F})$ is due to staining of the cell membrane lipids.

further up-regulation of sulfur oxidation did not occur, e.g., due to enzymatic rate limitation.

As an alternative to enzymatic regulation, the filaments may leave the overlapping zone of oxygen and sulfide in order to starve themselves of external electron donor or acceptor, thereby interrupting sulfur deposition. A negative chemotactic response to oxygen (Møller et al., 1985) presumably prevented the filaments from moving upward into the oxic section of the gradient system. Instead, they migrated downward into the anoxic and sulfidic section, where sulfide could no longer be oxidized to sulfur due to the lack of an electron acceptor. It is surprising that these filaments moved into the sulfidic zone, because elevated sulfide concentrations have previously been reported to be toxic for Beggiatoa spp. (Winogradsky, 1887; Keil, 1912; Nelson et al., 1986). However, all earlier studies were done under oxic conditions. Our study indicates that Beggiatoa sp. 35Flor can tolerate higher sulfide concentrations under anoxic conditions, whereas under oxic conditions high sulfide concentrations can cause cell death indirectly by inducing excessive sulfur accumulation.

\section{METABOLISM OF BEGGIATOA IN THE ANOXIC ZONE OF GRADIENT SYSTEMS}

The depletion of sulfur and polyhydroxyalkanoate inclusions together with the production of sulfide suggests that Beggiatoa sp. 35Flor reduced internal sulfur by oxidizing stored carbon in the anoxic part of the gradient system. It is not known which type of PHA was synthesized by Beggiatoa sp. 35Flor, but for the most frequent PHA, poly(3-hydroxybutyrate) (PHB), the reaction $\left[\mathrm{C}_{4} \mathrm{O}_{2} \mathrm{H}_{6}\right]_{n}+n \cdot 9 \mathrm{~S}^{0}+n \cdot 6 \mathrm{H}_{2} \mathrm{O} \rightarrow n \cdot 4 \mathrm{CO}_{2}+n \cdot 9 \mathrm{H}_{2} \mathrm{~S}$, which is $\mathrm{pH}$-neutral, is in agreement with the observed $\mathrm{pH}$ profiles. Oxidation of stored sulfur was most probably not performed by filaments of the anoxic subpopulation, as oxygen and nitrate, which are the electron acceptors known to be used by members of the Beggiatoaceae, were not present. This is supported by the fact that we did not observe a decrease in $\mathrm{pH}$ at the corresponding depth interval in the gradient medium, which would be a sign of sulfuric acid production through oxidation of sulfur with oxygen $\left(2 \mathrm{~S}+3 \mathrm{O}_{2}+2 \mathrm{H}_{2} \mathrm{O} \rightarrow 2 \mathrm{SO}_{4}^{2-}+4 \mathrm{H}^{+}\right)$or nitrate $\left(5 \mathrm{~S}+6 \mathrm{NO}_{3}^{-}+2 \mathrm{H}_{2} \mathrm{O} \rightarrow 5 \mathrm{SO}_{4}^{2-}+3 \mathrm{~N}_{2}+4 \mathrm{H}^{+}\right.$or $4 \mathrm{~S}+$ $3 \mathrm{NO}_{3}^{-}+7 \mathrm{H}_{2} \mathrm{O} \rightarrow 4 \mathrm{SO}_{4}^{2-}+3 \mathrm{NH}_{4}^{+}+2 \mathrm{H}^{+}$). Likewise, sulfur disproportionation would produce sulfuric acid $\left(4 \mathrm{~S}+4 \mathrm{H}_{2} \mathrm{O} \rightarrow\right.$ $\left.3 \mathrm{H}_{2} \mathrm{~S}+\mathrm{SO}_{4}^{2-}+2 \mathrm{H}^{+}\right)$. The filaments of the anoxic subpopulation seem to gain energy chemoorganotrophically from oxidation of PHA with sulfur. However, no accessible source of fixed carbon is present in the medium, so that the PHA must have been previously synthesized through $\mathrm{CO}_{2}$ fixation during chemolithotrophic growth on oxygen and sulfide at the oxygen-sulfide interface. Generation of PHA through excess $\mathrm{CO}_{2}$ fixation was not described for Beggiatoa spp. so far, but is known from other bacteria (Schlegel et al., 1961). By reducing stored sulfur with a carbon reserve compound created previously through costly $\mathrm{CO}_{2}$ fixation, the filaments did not exploit environmental resources in the anoxic environment. Instead, this process might be used by Beggiatoa sp. 35Flor as the only possibility to empty storage space under high sulfide fluxes.

The presence of filamentous Beggiatoaceae in the anoxic section of oxygen-sulfide gradient systems has so far been shown in multiple laboratory and field studies (Sweerts et al., 1990; Mussmann et al., 2003; Kamp et al., 2006; Hinck et al., 2007; Preisler et al., 2007; Jørgensen et al., 2010). However, in these systems nitrate was present either externally or internally and could have been used for oxidizing reduced sulfur compounds in the anoxic zone of the sediment. Nitrate respiration could, however, be excluded in our experiments as $\mathrm{NO}_{\mathrm{X}}$ compounds were absent from medium and filaments.

\section{THE ROLE OF SULFUR REDUCTION BY BEGGIATOA spp. IN THE ENVIRONMENT}

The migration behavior and sulfur reduction by Beggiatoa filaments described in our study may occur and play the same role also in natural habitats. This is supported by the fact that the sulfide fluxes in our cultures (Table 1) were well within the range of fluxes previously measured in different natural Beggiatoa mats (Table 2), and that a strong heterogeneity in internal sulfur content of Beggiatoa filaments was also observed for filaments collected from natural mats (Sassen et al., 1993; Bernard and Fenchel, 1995). We suggest that, in natural habitats, filaments respond to high sulfide fluxes either by moving laterally to an adjacent region with a lower flux or, if this is not possible, by migrating vertically into the sulfidic and anoxic sediment section below, where they respire sulfur (Figure 4). However, the conditions at which 
Table 2 | Diffusive sulfide fluxes in natural Beggiatoa spp. mats.

\begin{tabular}{|c|c|c|c|}
\hline Sediment from & Measured & $\begin{array}{l}\text { Flux (mmol } \\
\left.\mathrm{m}^{-2} \mathrm{day}^{-1}\right)\end{array}$ & Reference \\
\hline Lagoon & ex situ & 38 & $\begin{array}{l}\text { Jørgensen and } \\
\text { Revsbech (1983) }\end{array}$ \\
\hline Arctic lagoon & ex situ & 34 & $\begin{array}{l}\text { Jørgensen et al. } \\
(2010)\end{array}$ \\
\hline Coast & ex situ & $4.3 \pm 2$ & Preisler et al. (2007) \\
\hline Harbor $^{a}$ & ex situ & ca. 12-100 & $\begin{array}{l}\text { Fenchel and Bernard } \\
\text { (1995) }\end{array}$ \\
\hline Deep sea mud volcano & ex situ & $13 \pm 4$ & de Beer et al. (2006) \\
\hline Deep sea mud volcano & in situ & $19 \pm 3$ & de Beer et al. (2006) \\
\hline Deep sea mud volcano & in situ & 11.6 & $\begin{array}{l}\text { Lichtschlag et al. } \\
\text { (2010) }\end{array}$ \\
\hline Deep sea mud volcano & in situ & 40 & Grünke et al. (2011) \\
\hline
\end{tabular}

All fluxes were calculated based on sulfide profiles obtained with microsensors (silver-silver or Clark type electrodes). When possible, values are given as average $\pm S D$ of parallel measurements.

${ }^{a}$ Minimum and maximum values were estimated from a graph presented in the cited study.

these phenomena occur will depend on the possible maximum oxidation rates of sulfide and ultimately sulfur, which likely define the tolerance of different Beggiatoa species toward high sulfide fluxes.

\section{ACKNOWLEDGMENTS}

We thank Martina Meyer and Kirsten Imhoff for technical support. We also thank the two reviewers for their useful comments and suggestions. The study was funded by the European Research Council (No. 203364-ELNOX), the Max Planck Society and the German National Merit Foundation.

\section{REFERENCES}

Bernard, C., and Fenchel, T. (1995). Mats of colourless sulphur bacteria 2. Structure, composition of biota and successional patterns. Mar. Ecol. Prog. Ser. 128, 171-179.

Brock, J., and Schulz-Vogt, H. N. (2011). Sulfide induces phosphate release from polyphosphate in cultures of a marine Beggiatoa strain. ISME J. 5 , 497-506.

de Beer, D., Sauter, E., Niemann, H., Kaul, N., Foucher, J.-P., Witte, U., Schlüter, M., and Boetius, A. (2006). In situ fluxes and zonation of microbial activity in surface sediments of the Håkon Mosby Mud Volcano. Limnol. Oceanogr. 51, 1315-1331.

Farquhar, G. J., and Boyle, W. C. (1971). Identification of filamentous microorganisms in activated sludge. J. Water Pollut. Control Fed. 43, 604-622.

Faust, L., and Wolfe, R. S. (1961). Enrichment and cultivation of Beggiatoa alba. J. Bacteriol. 81, 99-106.
Fenchel, T., and Bernard, C. (1995). Mats of colourless sulphur bacteria 1. Major microbial processes. Mar. Ecol. Prog. Ser. 128, 161-170.

Fossing, H., Gallardo, V. A., Jørgensen, B. B., Hüttel, M., Nielsen, L. P., Schulz, H., Canfield, D. E., Forster, S., Glud, R. N., Gundersen, J. K., Küver, J., Ramsing, N. B., Teske, A., Thamdrup, B., and Ulloa, O. (1995). Concentration and transport of nitrate by the mat-forming sulfur bacterium Thioploca. Nature 374, 713-715.

Grünke, S., Felden, J., Lichtschlag, A., Girnth, A.-C., de Beer, D., Wenzhöfer, F., and Boetius, A. (2011). Niche differentiation among matforming, sulfide-oxidizing bacteria at cold seeps of the Nile Deep Sea Fan (Eastern Mediterranean Sea). Geobiology 9, 330-348.

Hinck, S., Neu, T. R., Lavik, G., Mussmann, M., de Beer, D., and Jonkers, H. M. (2007). Physiological adaptation of a nitrate-storing

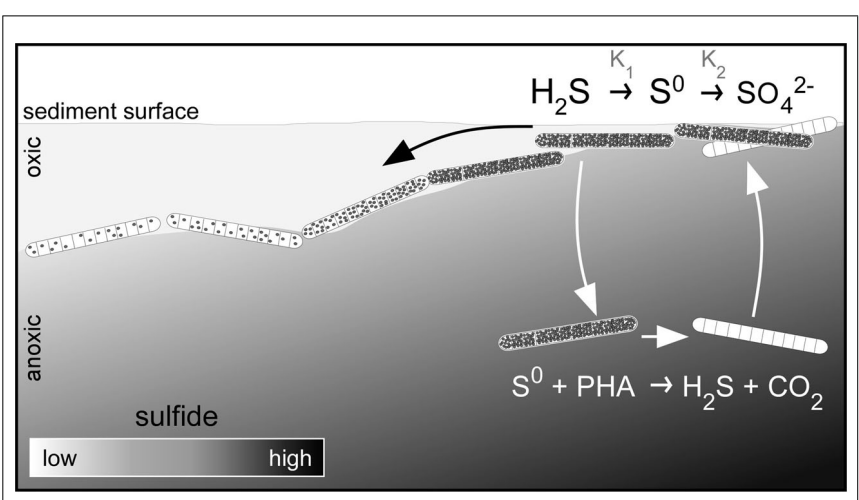

FIGURE 4 | Proposed function of sulfur reduction as a survival strategy of Beggiatoa spp. under high sulfide fluxes. In locations with high sulfide fluxes (right side) filaments become excessively filled with sulfur (black dots inside the filaments), because the oxidation rates of sulfide to sulfur $\left(K_{1}\right)$ and sulfur to sulfate $\left(K_{2}\right)$ are not well balanced $\left(K_{1}>K_{2}\right)$. To prevent bursting, the filaments could move into a region with a lower sulfide flux (black arrow) where these two reactions may proceed in a balanced way. If this is not possible, filaments could leave the oxygen-sulfide interface and move down into the anoxic region to reduce their internal sulfur deposits and thus prevent bursting (white arrow). They do so by using internally stored $\mathrm{PHA}$ as an electron donor to reduce $\mathrm{S}^{0}$ to $\mathrm{H}_{2} \mathrm{~S}$. After emptying storage space, the filaments return to the oxygen-sulfide interface, and continue with aerobic sulfide oxidation.

\section{SUPPLEMENTARY MATERIAL}

The Movie S1 for this article can be found online at http:// www.frontiersin.org/Microbial_Physiology_and_Metabolism/10. 3389/fmicb.2011.00276/abstract

Movie S1 |Time-lapse video of Beggiatoa sp. 35Flor filaments cultivated under low and high sulfide flux conditions. In presence of a low sulfide flux the filaments stay in a confined layer whereas pronounced downward migration is evident in cultures with a high sulfide flux.

Beggiatoa sp. to diel cycling in a phototrophic hypersaline mat. Appl. Environ. Microbiol. 73, 7013-7022.

Høgslund, S., Revsbech, N. P., Kuenen, J. G., Jørgensen, B. B., Gallardo, V. A., van de Vossenberg, J., Nielsen, J. L., Holmkvist, L., Arning, E. T., and Nielsen, L. P. (2009). Physiology and behaviour of marine Thioploca. ISME J. 3, 647-657.

Jørgensen, B. B. (1977). Distribution of colorless sulfur bacteria (Beggiatoa spp.) in a coastal marine sediment. Mar. Biol. 41, 19-28.

Jørgensen, B. B., Dunker, R., Grünke, S., and Røy, H. (2010). Filamentous sulfur bacteria, Beggiatoa spp., in arctic marine sediments (Svalbard, 79 degrees N). FEMS Microbiol. Ecol. $73,500-513$.

Jørgensen, B. B., and Revsbech, N. P. (1983). Colorless sulfur bacteria, Beggiatoa spp. and Thiovulum spp. in $\mathrm{O} 2$ and $\mathrm{H} 2 \mathrm{~S}$ microgradients. Appl. Environ. Microbiol. 45, 1261-1270.
Kamyshny, A., Borkenstein, C. G., and Ferdelman, T. G. (2009). Protocol for quantitative detection of elemental sulfur and polysulfide zero-valent sulfur distribution in natural aquatic samples. Geostand. Geoanal. Res. 33, 415-435.

Kalanetra, K. M., Huston, S. L., and Nelson, D. C. (2004). Novel, attached, sulfur-oxidizing bacteria at shallow hydrothermal vents possess vacuoles not involved in respiratory nitrate accumulation. Appl. Environ. Microbiol. 70, 7487-7496.

Kalanetra, K. M., Joye, S. B., Sunseri, N. R., and Nelson, D. C. (2005). Novel vacuolate sulfur bacteria from the Gulf of Mexico reproduce by reductive division in three dimensions. Environ. Microbiol. 7, 1451-1460.

Kamp, A., Røy, H., and Schulz-Vogt, H. N. (2008). Video-supported analysis of Beggiatoa filament growth, breakage, and movement. Microb. Ecol. 56, 484-491. 
Kamp, A., Stief, P., and Schulz-Vogt, H. N. (2006). Anaerobic sulfide oxidation with nitrate by a freshwater Beggiatoa enrichment culture. Appl. Environ. Microbiol. 72, 4755-4760.

Keil, F. (1912). Beiträge zur Physiologie der farblosen Schwefelbakterien. Beitr. Biol. Pflanz. 11, 335-372.

Lichtschlag, A., Felden, J., Brüchert, V., Boetius, A., and de Beer, D. (2010). Geochemical processes and chemosynthetic primary production in different thiotrophic mats of the Hakon Mosby Mud Volcano (Barents Sea). Limnol. Oceanogr. 55, 931949.

Macalady, J. L., Lyon, E. H., Koffman, B., Albertson, L. K., Meyer, K., Galdenzi, S., and Mariani, S. (2006). Dominant microbial populations in limestonecorroding stream biofilms, Frasassi cave system, Italy. Appl. Environ. Microbiol. 72, 5596-5609.

McHatton, S. C., Barry, J. P., Jannasch, H. W., and Nelson, D. C. (1996). High nitrate concentrations in vacuolate, autotrophic marine Beggiatoa spp. Appl. Environ. Microbiol.62, 954-958.

Millero, F. J., Plese, T., and Fernandez, M. (1988). The dissociation of hydrogen sulfide in seawater. Limnol. Oceanogr. 33, 269-274.

Møller, M. M., Nielsen, L. P., and Jørgensen, B. B. (1985). Oxygen responses and mat formation by Beggiatoa spp. Appl. Environ. Microbiol. 50, 373-382.

Mussmann, M., Schulz, H. N., Strotmann, B., Kjær, T., Nielsen, L. P., Rosselló-Mora, R. A., Amann, R. I., and Jørgensen, B. B. (2003). Phylogeny and distribution of nitratestoring Beggiatoa spp. in coastal marine sediments. Environ. Microbiol. 5, 523-533.

Nelson, D. C., and Castenholz, R. W. (1982). Light responses of Beggiatoa. Arch. Microbiol. 131, 146-155.

Nelson, D. C., and Jannasch, H. W. (1983). Chemoautotrophic growth of a marine Beggiatoa in sulfidegradient cultures. Arch. Microbiol. 136, 262-269.

Nelson, D. C., Jørgensen, B. B., and Revsbech, N. P. (1986). Growth-pattern and yield of a chemoautotrophic Beggiatoa sp. in oxygen-sulfide microgradients. Appl. Environ. Microbiol. 52, 225-233.

Nelson, D. C., Waterbury, J. B., and Jannasch, H. W. (1982). Nitrogen fixation and nitrate utilization by marine and fresh-water Beggiatoa. Arch. Microbiol. 133, 172-177.

Preisler, A., Lichtschlag, A., Lavik, G., Boetius, A., Jørgensen, B. B., and de Beer, D. (2007). Biological and chemical sulfide oxidation in a Beggiatoa inhabited marine sediment. ISME J. 1, 341-353.

Salman, V., Amann, R., Girnth, A.-C., Polerecky, L., Bailey, J. V., Høgslund, S., Jessen, G., Pantoja, S., and SchulzVogt, H. N. (2011). A single-cell sequencing approach to the classification of large, vacuolated sulfur bacteria. Syst. Appl. Microbiol. 34, 243-259.

Sassen, R., Roberts, H. H., Aharon, P., Larkin, J., Chinn, E. W., and Carney,
R. (1993). Chemosynthetic bacterial mats at cold hydrocarbon seeps, Gulf of Mexico continental slope. Org. Geochem. 20, 77-89.

Sayama, M. (2001). Presence of nitrateaccumulating sulfur bacteria and their influence on nitrogen cycling in a shallow coastal marine sediment. Appl. Environ. Microbiol. 67, 3481-3487.

Sayama, M., Risgaard-Petersen, N. Nielsen, L. P., Fossing, H., and Christensen, P. B. (2005). Impact of bacterial NO3-transport on sediment biogeochemistry. Appl. Environ. Microbiol. 71, 7575-7577.

Schlegel, H. G., Vonbartheld, R., and Gottschalk, G. (1961). Formation and utilization of poly-betahydroxybutyric acid by Knallgas bacteria (Hydrogenomonas). Nature 191, 463-465.

Schmidt, T. M., Arieli, B., Cohen, Y. Padan, E., and Strohl, W. R. (1987). Sulfur metabolism in Beggiatoa alba. J. Bacteriol. 169, 5466-5472.

Schulz, H. N., Brinkhoff, T., Ferdelman, T. G., Marine, M. H., Teske, A., and Jørgensen, B. B. (1999). Dense populations of a giant sulfur bacterium in Namibian shelf sediments. Science 284, 493-495.

Schulz, H. N., and de Beer, D. (2002). Uptake rates of oxygen and sulfide measured with individual Thiomargarita namibiensis cells by using microelectrodes. Appl. Environ. Microbiol. 68, 5746-5749.

Sweerts, J. P. R. A., De Beer, D., Nielsen, L. P., Verdouw, H., Van den Heuvel,
J. C., Cohen, Y., and Cappenberg, T. E. (1990). Denitrification by sulphur oxidizing Beggiatoa spp. mats on freshwater sediments. Nature 344, 762-763.

Weiss, R. F. (1970). Solubility of nitrogen, oxygen and argon in water and seawater. Deep Sea Res. 17, 721-735.

Winogradsky, S. (1887). Über Schwefelbakterien. Bot. Ztg. 45, 489-610.

Conflict of Interest Statement: The authors declare that the research was conducted in the absence of any commercial or financial relationships that could be construed as a potential conflict of interest.

Received: 22 September 2011; accepted: 23 December 2011; published online: 09 January 2012.

Citation: Schwedt A, Kreutzmann $A-C$, Polerecky $L$ and Schulz-Vogt $H N$ (2012) Sulfur respiration in a marine chemolithoautotrophic Beggiatoa strain. Front. Microbio. 2:276. doi: 10.3389/fmicb.2011.00276

This article was submitted to Frontiers in Microbial Physiology and Metabolism, a specialty of Frontiers in Microbiology.

Copyright ( $\odot 2012$ Schwedt, Kreutzmann, Polerecky and Schulz-Vogt. This is an open-access article distributed under the terms of the Creative Commons Attribution Non Commercial License, which permits non-commercial use, distribution, and reproduction in other forums, provided the original authors and source are credited. 